\title{
Gamma $(\gamma)$-mangostin attenuated gastric ulcers induced by absolute alcohol in rats: Histological, immunohistochemical and biochemical investigation
}

\section{Sarwan W. Bradosty}

Cihan University

\section{Saber W. Hamad}

Salahaddin University - Erbil College of Agricultural Engineering Sciences

Faiyaz Khudaboddin Shaikh ( $\sim$ faizbiochem@gmail.com )

Dr Babasaheb Ambedkar Marathwada University https://orcid.org/0000-0002-5735-4761

Nadir Mustafa Nanakali

Cihan University

Hero Helal Muhammed saed

University of Gramian

Suhyla Hamad Shareef

Cihan University

Nabaz FisalShakir Agha

Erbil Polytechnic University

Jamal Hussaini

MARA University of Technology: Universiti Teknologi MARA

Morteta H. Al-Medhtiy

University of Kufa

Mahmood Ameen Abdulla

Cihan University

Faruk Suzergoz

Harran University: Harran Universitesi

\section{Research Article}

Keywords: gamma ( ( )-mangostin, Gastroprotective, Anti-ulcer, Anti-oxidative enzymes, HSP70, Bax

Posted Date: July 29th, 2021

DOI: https://doi.org/10.21203/rs.3.rs-470823/v1 
License: (c) (i) This work is licensed under a Creative Commons Attribution 4.0 International License. Read Full License 


\section{Abstract}

Garcinia mangostana L. (Clusiaceae) principally contains gamma (y)-mangostin, a xanthone that exhibits a wide spectrum of bioactivities. The current study was aimed to establish the gastroprotective effect of this compound in ethanol-induced gastric mucosal injuries in rats. Experimental Sprague Dawley $(S D)$ rats $(n=30)$ were arbitrarily alienated into 5 groups $(n=6)$ : negative control $(10 \%$ Tween 20$)$, ulcer control (10\% Tween $20+5 \mathrm{ml} / \mathrm{kg}$ absolute alcohol), reference control $(5 \mathrm{ml} / \mathrm{kg}$ absolute alcohol $+20 \mathrm{mg} / \mathrm{kg}$ omeprazole), and two experimental groups $(5 \mathrm{ml} / \mathrm{kg}$ absolute alcohol $+10 \mathrm{mg} / \mathrm{kg} \gamma$-mangostin and $5 \mathrm{ml} / \mathrm{kg}$ absolute alcohol $+20 \mathrm{mg} / \mathrm{kg}$ - -mangostin). After successful oral feeding, all rats were anesthetized and sacrificed. Gastro-histology highlighted severe injuries to the gastric mucosa with decrease in gastric mucosal content and gastric juice pH in ulcer control group. y-mangostin (10 mg/kg \& $20 \mathrm{mg} / \mathrm{kg}$ ) showed strong gastroprotective effect by enhancing gastric mucosal content and gastric juice $\mathrm{pH}$ compared to the ulcer group, comparable to the omeprazole. Immuno-histochemical analysis revealed that $\gamma^{-}$ mangostin found to upregulate mucosal Hsp70 protein, and down-regulate Bax proteins. The biochemical analysis of mucosal tissue homogenate showed significant antioxidant activity with increase in SOD and CAT activities, whereas MDA was significantly decreased at $p<0.001$. The histological, immunohistochemical and biochemical analysis evidenced gastroprotective effects of $y$-mangostin that are attributed to its potential to inhibit alcohol induced oxidative stress. Specifically, $\gamma$-mangostin improved histology of mucosal content and enhanced anti-oxidative enzymes (SOD \& CAT) with decreasing lipid peroxidation (MDA). Furthermore dose dependent administration of $\mathrm{y}$-mangostin down-regulated expression of Bax protein and up-regulated HSP70.

\section{Introduction}

Gastric ulcers or peptic ulcers are a common disorder distressing a significant proportion of the human population and contributes to morbidity and mortality worldwide. Several factors provoke the progression of gastric ulcers including alcohol consumption, Helicobacter pylori infection, stress, cigarette smoking, malnutrition, and nonsteroidal anti-inflammatory drugs (Sidahmed et al. 2013; Dhiyaaldeen et al. 2014; Al-Wajeeh et al. 2017). The extensive vascular injuries to the stomach and small intestine with gastric cell necrosis are endorsed by gastric ulcers. Absolute ethanol is a well-known necrotizing inducer that induces gastric vascular injuries with gastric cell necrosis, resulting in progression in gastric ulcer (Abdulla et al. 2010, Wasman et al. 2011; Sidahmed et al. 2015; Ibrahim et al. 2016). Literature review suggests that absolute alcohol-mediated gastric ulcers enhance the level of reactive oxygen species (ROS) in gastric tissues (AlRashdi et al. 2012; Al Batran et al. 2013; Nordin et al. 2014; Salama et al 2016; Saremi et al. 2019; Fahmy et al. 2020). The high level of ROS is accountable for substantial injuries to vascular tissues in the stomach and intestine (Gwaram et al. 2016; Tayeby et al. 2017). The ROS are known for downregulation of heat shock protein 70 (HSP70) and up-regulation of proapoptotic $\mathrm{Bcl}$ 2-associated $\mathrm{X}$ protein (Bax) expressions (Al-Wajeeh et al. 2016; Fahmy et al. 2020). The HSP70 protein is a member of molecular chaperones that are involved in the primary folding of (client) proteins and plays a vital role in accelerating gastric ulcer healing (Abdulla et al. 2010; Park and Seo 2015). Conversely, Bax proteins are 
apoptotic activators involved in angiogenesis and play a critical role in tumor growth and progression (Abdulla et al. 2010). The ROS scavenging in gastric tissues by anti-oxidative enzymes namely superoxide dismutase (SOD) and catalase (CAT) prevents the production of gastric ulcers (Wong et al. 2013; Gwaram et al. 2016; Tayeby et al. 2017).

Traditional medications encompassing phytochemicals isolated from medicinal plants and herbs are reported to have curative effects against gastric ulcers and other gastrointestinal ailments. Continues efforts are undertaken to identify such phytoconstituents from scientific communities worldwide, as they have long been considered safe and effective agents against gastric ulcers. The gastroprotective activity of several medicinal plants and herbs is reported in the literature by several researchers (Abdulla et al. 2009; Mahmood et al. 2011; Taha et al. 2012; Golbabapour et al. 2013; Ab Rahim et al. 2014; Hajrezaie et al. 2015; Omar et al. 2017; Rahman et al. 2019). However molecular characterizations of these plant extracts, identification of gastroprotective phytoconstituents, and establishing of the anti-ulcer potential of such compounds are needed for the development of effective drugs to suppress gastric ulcers.

Mangosteen (Garcinia mangostana L.) is edible fruit possessing a plethora of health-promoting compounds including xanthones, a-mangostin, and $\mathrm{y}$-mangostin. These are characteristic polyphenolic compounds possessing a tricyclic aromatic ring system and found to accumulate in the pericarp of the fruit. Mangosteen is used in the traditional medicine of South East Asia for the treatment of Alzheimer's disease, obesity, diarrhea, urinary tract infections, gonorrhea, and so on (Abdulla et al. 2009). Mangosteen also exerts biological activities specifically anti-inflammatory, hepatoprotective anticarcinogenic, antioxidant, antiviral, and so on (Akao et al. 2008, Abood et al. 2020). From its discovery years back to 1855 (Schmid, 1855), a-mangostin has been reported to be major contributors of all biological activities of mangosteen with less evidence on $y$-mangostin. However, $y$-mangostin possesses anti-inflammatory, anti-osteoarthritis, anti-brain tumor activities, and effective in colon cancer prevention (Chang and Yang, 2012; Chiu et al. 2020).

In this study, we aimed to examine the gastroprotective effects of $Y$-mangostin. The current study focused on the investigation of gross morphology, histology, immunohistochemistry, and antioxidative enzymes of gastric tissues of rats upon dose-dependent administration of $y$-mangostin in ethanol-induced gastric ulcers in the rats. The investigation used omeprazole as a reference gastroprotective agent to equate the effectiveness of $y$-mangostin. Omeprazole act as an inhibitor of the proton pump and works by declining the amount of acid in the stomach. Several researchers used omeprazole as a reference drug against ethanol-induced gastric ulcers in rats (Halabi et al. 2014; Rouhollahi et al. 2014; Salama et al. 2016; Saremi, et al. 2019).

\section{Material And Methods}

\section{Chemicals and drugs}


Chemicals used in this study were procured from Sigma-Aldrich (USA). Omeprazole was procured from University of Malaya Medical Center Pharmacy and was used as the reference drug. Omeprazole was dissolved in $10 \%$ Tween $20(\mathrm{v} / \mathrm{v})$ and administered $(20 \mathrm{mg} / \mathrm{kg} ; 5 \mathrm{~mL} / \mathrm{kg})$ orally to rats as recommended earlier (Abdulla et al. 2009; Wasman et al. 2010).

\section{Experimental animals and ethical statement}

Mature healthy SD rats, 200-220 grams in weight were obtained from Experimental Animal House, Faculty of Medicine, University of Malaya. The Ethics Committee for Animal Experimentation, Faculty of Medicine, University of Malaya, Malaysia, was responsible for ethical approval under Ethical approval no. $\mathrm{BMS} / 22 / 11 / 2019 / \mathrm{MAA}(\mathrm{R})$ dated on 22/11/2019. The criteria defined in the "Guide for the Care and use of Laboratory Animals" set by the National Academy of Sciences and published by the National Institute of Health were applied for humane attention towards experimental rats.

\section{Induction of acute gastric lesion}

The experimental rats were kept independently in cages with wide mesh wire bottom to avoid coprophagy. The rats were nourished with standard pellets diet and free tap water ad libitum. Rats were divided randomly into five groups of six rats each.

Overnight fasted animals were treated as follows:

Group 1 (normal control) \& group 2 (ulcer control) fed with vehicle (10\% Tween $20 \mathrm{v} / \mathrm{v}, 5 \mathrm{ml} / \mathrm{kg}$ ). Group 3 (gastroprotective group) fed with omeprazole $20 \mathrm{mg} / \mathrm{kg}$ in vehicle $(5 \mathrm{ml} / \mathrm{kg})$. Group 4 \& 5 (experimental

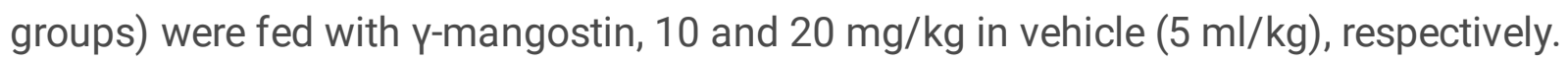

After 60 minutes, all groups except group 1 (normal control) were aggravated through the gastric intubation of absolute ethanol $(5 \mathrm{ml} / \mathrm{kg})$. After period of 60 minutes, all rats anesthetized using universal anesthesia i.e. Ketamine $(30 \mathrm{mg} / \mathrm{kg}, 100 \mathrm{mg} / \mathrm{mL})$. The rats were then sacrificed and their stomachs were removed immediately instantaneously (Abdulla et al. 2010; Ketuly et al. 2011).

\section{Macroscopic examination of gastroprotective assessments}

For the gross analysis of gastric mucosa, isolated stomachs were opened along the greater curvature and washed with ice normal saline $(0.9 \% \mathrm{NaCl})$. The resulting tissue sections were examined for injuries with a dissecting microscope. Gastric ulcers were observed on the gastric tissues as elongated bands of red hemorrhagic lesions and were parallel to the long axis of the stomach. The length, area and \% inhibition of ulcers area were calculated by using following formulas (Noor et al. 2006; Wasman et al. 2011; Ibrahim et al. 2012).

The length $(\mathrm{mm})$ and width $(\mathrm{mm})$ of hemorrhagic band was measured using planimeter

[(10 $\mathrm{mm} \times 10 \mathrm{~mm}=$ ulcer area) under dissecting microscope $(1.8 \times)]$. 
The area of each ulcers lesion was measured by counting the number of small squares, $2 \mathrm{~mm} \times 2 \mathrm{~mm}$, covering the length and width of each hemorrhagic band. The sum of the areas of all lesions for each stomach was applied in the calculation of the ulcer area (UA)

Sum of small squares $\times 4 \times 1.8=\mathrm{UA} \mathrm{mm^{2 }}$.

The inhibition percentage (I \%) was calculated by the following formula

The inhibition percentage $(I \%)=$ UA control- UA treated / UA control X 100.

\section{Measurement of mucus content}

The gastric mucosa of each rat was gently rubbed off by a glass slide and the weight of the collected mucus was measured using precise electronic balance (Sidahmed et al. 2013).

\section{Measurement of gastric juice acid content $(\mathrm{pH})$}

The isolated gastric content were centrifuged at $4000 \mathrm{rpm}$ for $10 \mathrm{~min}$. and the resulting supernatants were evaluated for hydrogen ion concentration $(\mathrm{pH})$ by titration with $0.1 \mathrm{~N} \mathrm{NaOH}$ using a digital $\mathrm{pH}$ meter (Hanna instruments, Ann Arbor, MI, USA) and the acidity was reported in mEq/L (Abdulla et al. 2010).

\section{Histopathological evaluation}

For histopathological analysis, a specimen of stomach's glandular wall was immobile in 10\% buffered formalin solution and dehydrated with ethanol and xylene. Then each specimen were embedded in paraffin wax and sectioned at $5 \mu \mathrm{m}$ in slices by microtome (Leic a Rotation, Germany) (Fard et al. 2011). Follow-on slides were stained with hematoxylin and eosin (H \& E) stain and examined under light microscope (Salga et al. 2011; Hashim et al. 2012). To examine mucus production, the specimens of glandular portion of stomach were stained with periodic acid schiff (PAS) stain using Sigma's PAS Kit and changes in both acidic and basic glycoproteins were observed and analyzed as per manufacturer instructions (Fard et al. 2011; Gwaram et al. 2012).

\section{Immuno-histochemical evaluation}

Stomach specimens (5 $\mu \mathrm{m})$ was stained by ARKTM immunohistochemistry staining kit (Animal Research Kit) to locate HSP 70 (1:100) and Bax (1:50) proteins. Both proteins were procured from Santa Cruz Biotechnology, Inc., California, USA (Wong et al. 2013; Rouhollahi et al. 2014).

\section{Measurement of SOD, CAT and malondialdehyde (MDA)}

The glandular gastric wall tissues of each rat were washed with ice cold phosphate buffered saline (PBS). These tissues $(10 \% \mathrm{w} / \mathrm{v})$ were homogenized in ice cold potassium phosphate buffer $(10 \%[\mathrm{w} / \mathrm{v}], 50$ mmol, pH 7.8) containing mammalian protease inhibitor using homogenizer (Polytron, Heidolph RZR 1, Schwabach, Germany). The resultant homogenates were centrifuged at $10000 \mathrm{~g}$ for $15 \mathrm{~min}$ at $4^{\circ} \mathrm{C}$. The 
supernatants were considered as crude source of SOD, CAT and MDA. The levels of these parameters of anti-oxidation and lipid peroxidation were measured using commercially purchased kits following manufacturer protocols (Cayman, Chemical Co., Ann Arbor, USA) (Wong et al. 2013; , Halabi et al. 2014).

\section{Statistical analysis}

The results data were reported as mean \pm standard error of the mean (S. E. M., $n=6$ per group). The significant differences among the group means were reported using one-way analysis of variance (ANOVA) followed by the multiple comparisons using Tukey's post-hoc test. The results were reported as the statistical significance when $p<0.05$. Statistical analysis and figures were produced using JASP Team (2020). JASP (Version 0.14.1). [Computer software].

\section{Results}

\section{Effect of $\mathrm{Y}$-mangostin on ulcer area, mucus weights and $\mathrm{pH}$ of gastric content}

Ulcer area, mucus weights and $\mathrm{pH}$ of gastric content after 60 minutes of omeprazole or $\mathrm{y}$-mangostin treatments are revealed in Table 1. The one way ANOVA analysis of the results showed significant differences $(p<0.001)$ among all treated groups in the ulcer area and \% UA mm ${ }^{2}$ inhibition with $F(3,20)$ 12540.279 and $F(2,15) 338.162$ respectively. The Tukey's post-hoc multiple comparisons test analysis revealed that rats of ulcer control group showed vulnerability towards ethanol with development of gastric ulcer of size $734.17 \pm 3.76 \mathrm{~mm}^{2}$ in comparison to control group $(p<0.001)$. However, the rats fed by $\gamma$-mangostin with doses of $10 \mathrm{mg} / \mathrm{kg}$ and $20 \mathrm{mg} / \mathrm{kg}$ displayed significantly reduction $(p<0.001)$ in ulcer areas of stomach compared to ulcer control group. The flattening of gastric mucosal folds and insignificant mucosal injury were observed in these groups when compared with ulcer control group (Fig. 1B, C \& D). These results were comparable to the rats of normal group and rats treated with omeprazole, a reference drug (Fig. 1A \& E). These experimental groups produced significant rise in mucus contents of stomach when compared to ulcer control group, manifesting significant protection against ethanolassociated gastric ulcers in rats.

The one way ANOVA analysis suggests significant differences $(p<0.001)$ among all treated groups in the mucus weights with $F(4,25) 7437.912$. The Tukey's post-hoc multiple comparisons test analysis revealed that rats fed with $\gamma$-mangostin suppressed the vulnerability action of ethanol when compared to ulcer control group. In addition, experimental animals fed with $y$-mangostin significantly increased the $\mathrm{pH}$ of the gastric juices compared to ulcer control group with $\mathrm{F}$ value $(4,25) 906.967$ (Table 1).

Table 1 Effect of the $\gamma$-mangostin on the mucus weight, pH of gastric content, ulcer area, \% inhibition of ulcer area in stomach of rats. Data expressed as mean \pm S.E.M. ( $n=6$ /group). Statistical significant differences were examined using one way ANOVA and Tukey's posthoc 
tests. ${ }^{*} \mathrm{P}<0.0001$ compared with ulcer control group, ${ }^{\#} \mathrm{P}<0.0001$ compared with normal control group.

Animal groups

G1

Normal control
Pre-treatment

$(5 \mathrm{~mL} / \mathrm{kg})$

$10 \%$ Tween 20
Mucus

weight $(g)$
$\mathrm{pH}$

$3.27 \pm 0.02$
$5.83 \pm$ 0.01

G2

Ulcer control

10\% Tween 20

$1.19 \pm$

$0.03^{\#}$

$4.10 \pm$

$734.17 \pm$

0

G3 Omeprazole (20

$\mathrm{mg} / \mathrm{kg}$ )

$20 \mathrm{mg} / \mathrm{kg}$

omeprazole

$5.57 \pm$

$0.02^{\#}$

3.76"

G4

$\gamma$-mangostin (10

$\mathrm{mg} / \mathrm{kg}$ )

$\begin{array}{ll}10 \mathrm{mg} / \mathrm{kg} & 4.63 \pm \\ \gamma-\mathrm{mang} & 0.01 *\end{array}$

$\gamma$-mangostin

$0.01 *$

$6.11 \pm$

0.03*

$88.33 \pm$

$1.76^{*}$

$87.97 \pm$

$0.21 *$

G5

$\gamma$-mangostin (20

$\mathrm{mg} / \mathrm{kg}$ )

$20 \mathrm{mg} / \mathrm{kg}$ $\gamma$-mangostin
$5.26 \pm$

$0.02 *$

$5.48 \pm$

0.03*

$171.67 \pm$

3.76*

$76.61 \pm$

$0.44^{*}$

(\%) $(\mathrm{mm})^{2}$

\section{Effect of $Y$-mangostin on histological evaluation of ethanol-induced gastric ulcer in rats}

The histological result with $\mathrm{H} \& \mathrm{E}$ stain signified severe injury of the gastric mucosa, and lesions pierced deeply with subcutaneous edema and leukocytes infiltration in the ulcer control group (Fig. 2B) in comparison with normal control group where gastric epithelium were intact (Fig. 2A). The rats in the experimental groups with omeprazole and $y$-mangostin $(10 \mathrm{mg} / \mathrm{kg}$ and $20 \mathrm{mg} / \mathrm{kg}$ ) had markedly improved protection of gastric mucosa by the lessening or absence of the ulcer area, edema, less intrusion to the surface epithelium and leukocyte infiltration of submucosal layer (Fig. 2C, D \& E). Remarkably, $y$-mangostin lessened the histological changes and efficiently protected the stomach epithelium cell lining by decreasing provocative cell infiltration and submucosal edema in a dosedependent manner. Oral administrating $\mathrm{Y}$-mangostin at $10 \mathrm{mg} / \mathrm{kg}$ significantly improved gastric histological changes preserving structure like normal. The antiulcer effect of $y$-mangostin at $20 \mathrm{mg} / \mathrm{kg}$ was analogous to omeprazole.

As depicted in Fig. 3, PAS staining displayed decline of gastric mucosal secretion in the ulcer group as compared to normal group (Fig. 3A \& B). The progressive PAS staining of the mucosal lining in the $\gamma^{-}$ mangostin- treated groups ( $10 \mathrm{mg} / \mathrm{kg} \& 20 \mathrm{mg} / \mathrm{kg}$ ) showed increased in the PAS staining intensity of glycoprotein (magenta color), in comparison to ulcer control group (Fig. 3C \& D). These results were comparable to omeprazole treated group (Fig. 3E). These findings advocated that $\mathrm{y}$-mangostin possesses significant gastroprotective activity. 
Immuno-histochemical results shown that, the ethanol-induced ulcer group exhibited a significantly improved expression of Bax protein when compared with control rats (Fig. 4A \& B). In addition, the expression of HSP70 protein in ulcer group was considerably down-regulated in comparison to control rats (Fig. 5A \& B). In contrast, the Bax protein shown down-regulation of expression in rats feds with omeprazole and $y$-mangostin by the declined positive gastric epithelial cells stained in brown compared to ulcer group (Fig. 4C, D \& E). Whereas, the expression HSP70 protein was found to enhance significantly in experimental groups signifying cytoprotective effects of HSP70 protein on gastric mucosa ((Fig. 5C, D \& E). The modulatory effect of $Y$-mangostin on Bax and HSP 70 proteins expression was dose related, with better effect at the higher dose $(20 \mathrm{mg} / \mathrm{kg}$ ) where antigen site (shown by arrow) acquired browner stain in the cytoplasm of gastric epithelial cells.

\section{Effects of $\mathrm{Y}$-mangostin on SOD, CAT and MDA}

The one way ANOVA analysis of the data revealed substantial difference $(p<0.001)$ within all treated groups in the levels of SOD, CAT and MDA with $F(4,25)$ values $150.672,1334.577$ and 1295.868 respectively (Fig. 6). Rats in ulcer control group showed significantly lower SOD and CAT activities compared to normal group. Tukey's posthoc multiple comparisons test analysis shown that administration of ethanol lessens SOD and CAT actions significantly with improved MDA level $\left({ }^{\#} p<\right.$ 0.001). However, dose dependent administration of $\gamma$-mangostin induced a significant elevation of SOD and CAT in contrast to ulcer control group restoring levels of these enzymes close to normal and slightly comparable to omeprazole treated group ( $\left.{ }^{*} p<0.001\right)$. Rats fed with both doses $(10 \mathrm{mg} / \mathrm{kg} \mathrm{\&} 20 \mathrm{mg} / \mathrm{kg})$ of $y$-mangostin significantly lowered the MDA level compared to ulcer control group ( $\left.{ }^{*} p<0.001\right)$. Interestingly, rats fed with $10 \mathrm{mg} / \mathrm{kg} \mathrm{Y}$-mangostin were found to reduce MDA comparably more than omeprazole. MDA was used as marker for lipid peroxidation.

\section{Discussion}

Currently, there is worldwide interest in traditional alternative medicine. Several medicinal plants and their phytoconstituents have been evaluated as gastroprotective mediators reported earlier (Abdelwahab et al. 2013; Ibrahim et al. 2015; Zhou et al. 2020). Absolute alcohol is necrotizing inducer and frequently used to induce gastric ulcer in laboratory animals. Ethanol easily penetrates into the gastric mucosa and induced gastric damage. It causes disturbances in the mucus barrier layer of the stomach and decreases endogenous enzyme levels and the protective mucosal barrier of the gastric mucosa. Additionally, it increases the microvascular permeability as well as lipid peroxidation (MDA level increases). Furthermore, ethanol raises free radical production in the gastric mucosa resulting in the gastric mucosal injury (Salama et al. 2016; Fahmy et al. 2020). Absolute alcohol effusively injures the gastric epithelium leading to augmented polymorphonuclear neutrophil infiltration and edema in submucosal layer of gastric epithelium. The infiltration of neutrophils with edema of submucosal layer seems to be involved in the initial processes of gastric ulcer formation. 
The induction of gastric ulcers in experimental rats by ethanol is a most common experimental methods used to assess the antiulcer activity of plant extracts and their purified phytoconstituents (Qader et al. 2012; Sidahmed et al. 2015; Saremi et al. 2019). In the current study, gastric ulcers were induced in experimental rats with or without $y$-mangostin in the different groups. Absolute alcohol induced gastric ulcers in the ulcer control group revealed by gastric mucosal injury. The histopathological results revealed the protection of gastric mucosa and absence or reduction of edema and leukocyte infiltration into the subcutaneous layer of gastric wall of rats fed with $y$-mangostin along with absolute alcohol. Our findings corroborated the studies reporting the reduction of neutrophil infiltration with edema into gastric lesion encouraging the prevention gastric mucosal damage in rats upon administration of plants extracts (Kadir et al. 2014; Gwaram et al. 2016; Salga et al. 2017). Flattening of the gastric mucosal folds which increase the surface area, recommends that $y$-mangostin applies a gastroprotective effect against absolute alcohol. The relaxing of circular muscles protects the gastric mucosa by flattening the folds. This increases the surface mucosal area open to absolute alcohol and reduces the volume of the stomach irritations on the Rugel crest (Abdulla et al. 2010; Nordin et al. 2014; Omar et al. 20174).

In our study, administration of absolute alcohol produces ROS that down-regulates the expression of HSP 70 and up-regulates the expression of proapoptotic Bax proteins. HSP 70 protein protects stomach epithelial cells from ROS induced oxidative stress or heat shock created by absolute alcohol. HSP70 avoids partly denatured proteins from accumulating and permits them to refold. The up-regulation of HSP70 in experiment groups of our study recommends the protection of gastric epithelium. With the consistence of the results of present study numerous gastric ulcer researchers reported that up-regulation of HSP70 associated with gastric protection against absolute ethanol (Wong et al. 2013; Rouhollahi et al. 2014; Saremi et al. 2019). This outcome led us to hypothesize that the up-regulation of HSP70 protein synthesis might play an essential role in promoting the gastroprotective effect of $\gamma$-mangostin, possibly by attenuating ROS-mediated gastric oxidative stress. Similarly, numerous studies demonstrate that the upregulation of HSP70 in experimental animals protect stomach from necrotizing agents (Halabi et al. 2014; Nazarbahjat et al. 2016; AL-Wajeeh et al. 2017). The results of the current study revealed that stomach tissue homogenates from experimental groups showed expressively reduced levels of MDA and elevated levels of SOD and CAT in retort to oxidative stress induced by absolute ethanol. MDA is the final product of lipid peroxidation and is the indicator of lipid peroxidation in gastric tissues homogenate $\mathrm{Al}$ Batran et al. 2013; Dhiyaaldeen et al. 2014; Hajrezaie et al. 2015; Tayeby et al. 2017).

\section{Conclusion}

In nutshell, our study deciphered that, the $y$-mangostin exhibited significant gastroprotective effect in inhibition of stomach lesions against absolute ethanol induced gastric ulcer in rats confirmed by gross anatomy and histology. Experimental groups showed significantly increase in mucus secretion, rise in $\mathrm{pH}$ of gastric juice and reduction or absence of edema and leukocytes infiltration in submucosal layer. $\mathrm{Y}^{-}$ mangostin expressively raised CAT and SOD, and significantly reduced MDA in gastric tissue 
homogenate. Additionally, up-regulation of HSP 70 and down-regulation of Bax proteins in gastric epithelium of experiment groups, advocates anti-ulcer effect of $\gamma$-mangostin.

\section{Declarations}

\section{Declaration of Competing Interest}

The authors declare that they have no known competing financial interests or personal relationships that could have appeared to influence the work reported in this paper.

Authors' contribution: SWB, MAA, SWH, MHA: Conceived, designed and performed the experiments. SWB, FKS, MAA, SWH, JH: Data collection and analysis. FKS, MAA, SWB, HHM: Wrote and formatted manuscript for publication: NMN, NFSA, SHS, ASA, FK: Intellectual input and feedback to manuscript.

Funding acknowledgement: This study was financially supported by University of Malaya, Malaysia. The funders had no part in study proposal, data collection and analysis, decision to publish, or preparation of the manuscript.

\section{References}

Abdelwahab SI, Taha MM, Abdulla MA, et al (2013) Gastroprotective mechanism of Bauhinia thonningii Schum. J Ethnopharmacol 148:277-286. https://doi:10.1016/j.jep.2013.04.027

Abdulla MA et al. (2009) Evaluation of the anti-ulcer activities of Morus alba extracts in experimentallyinduced gastric ulcer in rats. Biomed Res 35-39.

Abdulla MA, Abdul-Aziz Ahmed K, Hussain AL-Bayaty F, Masood Y. (2010) Gastroprotective effect of Phyllanthus niruri leaf extract against ethanol-induced gastric mucosal injury in rats. Afr J Pharm Pharmacol 226-230

Abood WN, Bradosty SW, Shaikh FK, et al (2020) Garcinia mangostana peel extracts exhibit hepatoprotective activity against thioacetamide-induced liver cirrhosis in rats. J Funct Foods 74:104200. https://doi:10.1016/j.jff.2020.104200

Akao Y, Nakagawa Y, Nozawa Y (2008) Anti-Cancer Effects of Xanthones from Pericarps of Mangosteen. Int J Mol Sci 9:355-370. https://doi:10.3390/ijms9030355

Al Batran R, Al-Bayaty F, Ameen Abdulla M, et al (2013) Gastroprotective effects of Corchorus olitorius leaf extract against ethanol-induced gastric mucosal hemorrhagic lesions in rats. J Gastroenterol Hepatol 28:1321-1329. https://doi:10.1111/jgh.12229

AlRashdi AS, Salama SM, Alkiyumi SS, et al (2012) Mechanisms of Gastroprotective Effects of Ethanolic Leaf Extract of Jasminum sambaca gainst $\mathrm{HCl}$ /Ethanol-Induced Gastric Mucosal Injury in Rats. Evid 
AL-Wajeeh NS, Hajrezaei M, Al-Henhena N, et al (2017) The antiulcer effect of Cibotium barometz leaves in rats with experimentally induced acute gastric ulcer. Drug Des Devel Ther Volume11:995-1009. https://doi:10.2147/dddt.s107018

Aziz Ibrahim IA, Qader SW, Abdulla MA, et al (2012) Effects of Pithecellobium Jiringa Ethanol Extract against Ethanol-Induced Gastric Mucosal Injuries in Sprague-Dawley Rats. Molecules 17:2796-2811. https://doi: 10.3390/molecules17032796

Chang H-F, Yang L-L (2012) Gamma-Mangostin, a Micronutrient of Mangosteen Fruit, Induces Apoptosis in Human Colon Cancer Cells. Molecules 17:8010-8021. https://doi:10.3390/molecules17078010

Chiu Y-S, Wu J-L, Yeh C-T, et al (2020) Y-Mangostin isolated from Garcinia mangostana L. suppresses inflammation and alleviates symptoms of osteoarthritis via modulating miR-124-3p/IL-6/NF-KB signaling. Aging 12:6630-6643. https://doi:10.18632/aging.103003

Dhiyaaldeen SM, Amin ZA, Darvish PH, et al (2014) Protective effects of (1-(4-hydroxy-phenyl)-3-m-tolylpropenone chalcone in indomethacin-induced gastric erosive damage in rats. BMC Vet Res https://doi:10.1186/s12917-014-0303-7

Fahmy NM, Al-Sayed E, Michel HE, et al (2020) Gastroprotective effects of Erythrina speciosa (Fabaceae) leaves cultivated in Egypt against ethanol-induced gastric ulcer in rats. J Ethnopharmacol 248:112297. https://doi:10.1016/j.jep.2019.112297

Fard AA, Hajrezaie M, Kadir FA, et al (2011) The Effects of Combined Adiponectin-Metformin on Glucose and Lipids Levels in Mice and Acute Toxicity and Anti-Ulcerogenic Activity of Adiponectin Against Ethanol-Induced Gastric Mucosal Injuries in Rat. Molecules 16:9534-9552.

https://doi:10.3390/molecules16119534

Golbabapour S, Hajrezaie M, Hassandarvish P, et al (2013) Acute Toxicity and Gastroprotective Role of $M$. pruriens in Ethanol-Induced Gastric Mucosal Injuries in Rats. BioMed Res Int 2013:1-13. https://doi:10.1155/2013/974185

Gwaram NS, Musalam L, Ali HM, et al (2016) Synthesis, spectral characterization and biological activity of Zn(II) complex with 2'-[1-(2-hydroxyphenyl)ethylidene]benzenesulfanohydrazide. https://doi:10.1016/j.arabjc.2012.01.002

Hajrezaie M, Golbabapour S, Hassandarvish P, et al (2012) Acute Toxicity and Gastroprotection Studies of a New Schiff Base Derived Copper (II) Complex against Ethanol-Induced Acute Gastric Lesions in Rats. PLoS ONE. https://doi:10.1371/journal.pone.0051537

Hajrezaie M, Salehen NA, Karimian H, et al (2015) Biochanin A Gastroprotective Effects in EthanolInduced Gastric Mucosal Ulceration in Rats. PLOS ONE. https://doi:10.1371/journal.pone.0121529 
Halabi MF, Shakir RM, Bardi DA, et al (2014) Gastroprotective Activity of Ethyl-4-[(3,5-di-tert-butyl-2hydroxybenzylidene) Amino]benzoate against Ethanol-Induced Gastric Mucosal Ulcer in Rats. PLoS ONE. https://doi:10.1371/journal.pone.0095908.

Hashim H, Mughrabi FF, Ameen M, et al (2012) Cytoprotective Effect of Benzyl N'-(5-Chloro-indol-3-ylmethylidene)-hydrazinecarbodithioate Against Ethanol-Induced Gastric Mucosal Injury in Rats. Molecules 17:9306-9320. https://doi:10.3390/molecules17089306

Ibrahim AA, Ameen Abdulla M, Hajrezaie M, et al (2015) The gastroprotective effects of hydroalcoholic extract of Monolluma quadrangula against ethanol-induced gastric mucosal injuries in Sprague Dawley rats. Drug Des Devel Ther 93. https://doi:10.2147/dddt.s91247

Kadir A, Zorofchian Moghadamtousi S, Rouhollahi E, et al (2014) Gastroprotective activity of Annona muricata leaves against ethanol-induced gastric injury in rats via Hsp70/Bax involvement. Drug Des Devel Ther 2099. https://doi: 10.2147/dddt.s70096

Ketuly KA et al. (2011) Anti-ulcer activity of the 9alpha-bromo analogue of Beclomethasone dipropionate against ethanol-induced gastric mucosal injury in rats. J Med Plants Res 514-520

Mahmood AA et al. (2011) Anti-ulcerogenic effects of Nagilla sativa in ethanol-induced gastric injuries in rats. J Med Plant Res 5577-5583

Nazarbahjat N, Kadir FA, Ariffin A, et al (2016) Antioxidant Properties and Gastroprotective Effects of 2(Ethylthio)Benzohydrazones on Ethanol-Induced Acute Gastric Mucosal Lesions in Rats. PLOS ONE. https://doi:10.1371/journal.pone.0156022.

Noor et al. (2006) Prevention of acute gastric mucosal lesions by R. hasseltii in rats. J Anim Vet Adv 161164.

Nordin N, Salama SM, Golbabapour S, et al (2014) Anti-Ulcerogenic Effect of Methanolic Extracts from Enicosanthellum pulchrum (King) Heusden against Ethanol-Induced Acute Gastric Lesion in Animal Models. PLoS ONE. https://doi: 10.1371/journal.pone.0111925

Omar H, Nordin N, Hassandarvish P, et al (2017) Methanol leaf extract of Actinodaphne sesquipedalis (Lauraceae) enhances gastric defense against ethanol-induced ulcer in rats. Drug Des Devel Ther Volume 11:1353-1365. https://doi:10.2147/dddt.s120564

Park C-J, Seo Y-S (2015) Heat Shock Proteins: A Review of the Molecular Chaperones for Plant Immunity. Plant Pathol J 31:323-333. https://doi: 10.5423/ppj.rw.08.2015.0150

Qader SW, Abdulla MA, Chua LS, et al (2012) Pharmacological Mechanisms Underlying Gastroprotective Activities of the Fractions Obtained from Polygonum minus in Sprague Dawley Rats. Int J Mol Sci 13:1481-1496. https://doi:10.3390/ijms13021481 
Rahim NA, Hassandarvish P, Golbabapour S, et al (2014) Gastroprotective Effect of Ethanolic Extract of Curcuma xanthorrhiza Leaf against Ethanol-Induced Gastric Mucosal Lesions inSprague-DawleyRats. BioMed Res Int 2014:1-10. https://doi:10.1155/2014/416409

Rahman Z, Dwivedi DK, Jena GB (2019) Ethanol-induced gastric ulcer in rats and intervention of tertbutylhydroquinone: Involvement of Nrf2/HO-1 signalling pathway. Hum Exp Toxicol 39:547-562. https://doi:10.1177/0960327119895559

Rouhollahi E, Zorofchian Moghadamtousi S, Hamdi OA, et al (2014) Evaluation of acute toxicity and gastroprotective activity of curcuma purpurascens BI. rhizome against ethanol-induced gastric mucosal injury in rats. BMC Compl Alternative Med https://doi:10.1186/1472-6882-14-378

Salama SM, Gwaram NS, AlRashdi AS, et al (2016) A Zinc Morpholine Complex Prevents HCl/EthanolInduced Gastric Ulcers in a Rat Model. Sci Rep https://doi:10.1038/srep29646

Salga MS, Ali HM, Abdulla MA, et al (2017) Synthesis and gastroprotective activities of some zinc (II) complexes derived from (E)-2-(1-(2-(piperazin-1-yl)ethylimino)ethyl)phenol and (E)-4-(1-(2-(piperazin-1yl)ethylimino)ethyl)benzene-1,3-diol Schiff bases against aspirin induced ulceration. Arab J Chem https://doi:10.1016/j.arabjc.2013.05.028

Salga MS, Ali HM, Abdullah MA, et al (2011) Mechanistic Studies of the Anti-Ulcerogenic Activity and Acute Toxicity Evaluation of Dichlorido-Copper(II)-4-(2-5-Bromo-benzylideneamino)ethyl) Piperazin-1-ium Phenolate Complex against Ethanol-Induced Gastric Injury in Rats. Molecules 16:8654-8669. https://doi:10.3390/molecules16108654

Saremi K, Rad SK, Tayeby F, et al (2019) Gastroprotective activity of a novel Schiff base derived dibromo substituted compound against ethanol-induced acute gastric lesions in rats. BMC Pharmacol Toxicol https://doi:10.1186/s40360-019-0292-z

Schmid W. (1855) Ueber das mangostin Justus Liebigs Annalen - Chem 83-88

Sidahmed HM, Azizan AH, Mohan S, et al (2013) Gastroprotective effect of desmosdumotin C isolated from Mitrella kentii against ethanol-induced gastric mucosal hemorrhage in rats: possible involvement of glutathione, heat-shock protein-70, sulfhydryl compounds, nitric oxide, and anti-Helicobacter pylori activity. BMC Compl Alternative Med https://doi:10.1186/1472-6882-13-183

Sidahmed HM, Hashim NM, Abdulla MA, et al (2015) Antisecretory, Gastroprotective, Antioxidant and AntiHelicobcter Pylori Activity of Zerumbone from Zingiber Zerumbet (L.) Smith. PLOS ONE. https://doi:10.1371/journal.pone.0121060

Taha MM, Salga MS, Ali HM, et al (2012) Gastroprotective activities of Turnera diffusa Willd. ex Schult. revisited: Role of arbutin. J Ethnopharmacol 141:273-281. https://doi:10.1016/j.jep.2012.02.030 
Tayeby F, Salman AA, Kamran S, et al (2017) Ulcer Prevention Effect Of 3,4,5-Tihydroxy-NO-[(2-Methyl-1HIndol-3yl)Methylidene]Benzohydrazide In HCl/Ethanol-Induced Gastric Mucosal Damage In Rats. Int J Med Sci 14:1317-1326. https://doi:10.7150/ijms.20984

Wasman SQ, Mahmood AA, Chua LS, Alshawsh MA, Hamdan S. (2011) Antioxidant and gastroprotective activities of Andrographis paniculate (Hempedu Bumi) in Sprague Dawley rats. Indian J Exp Biol 49: 767772

Wong J-Y, Abdulla MA, Raman J, et al (2013) Gastroprotective Effects of Lion's Mane MushroomHericium erinaceus(Bull.:Fr.) Pers. (Aphyllophoromycetideae) Extract against Ethanol-Induced Ulcer in Rats. Evid Based Complement Alternat Med 2013:1-9. https://doi:10.1155/2013/492976

Zhou D, Yang Q, Tian T, et al (2020) Gastroprotective effect of gallic acid against ethanol-induced gastric ulcer in rats: Involvement of the Nrf2/HO-1 signaling and anti-apoptosis role. Biomed Pharmacother 126:110075. https://doi:10.1016/j.biopha.2020.110075

\section{Figures}




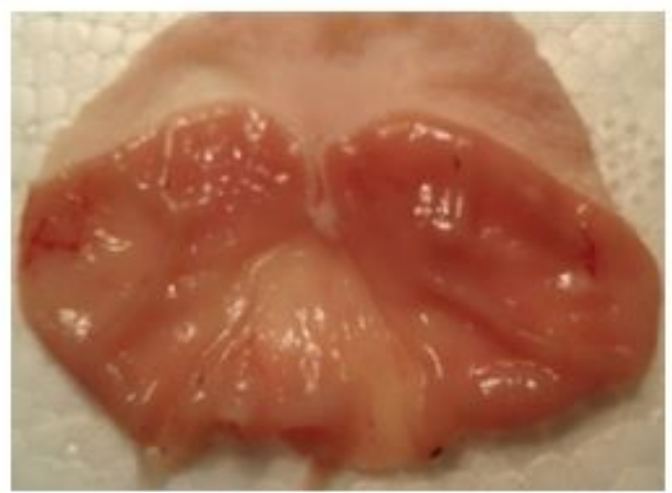

A

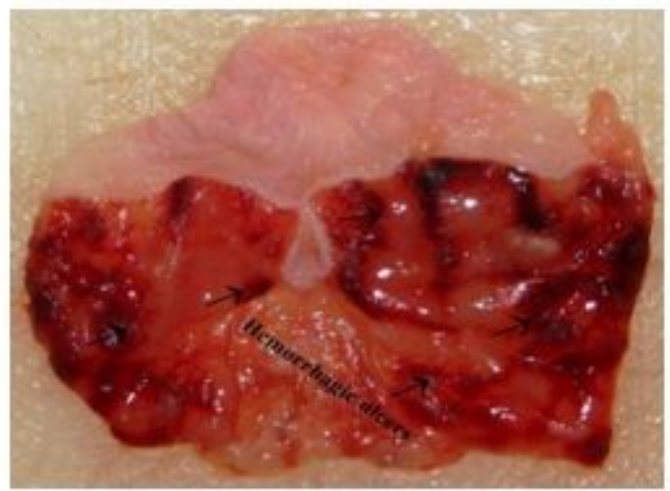

B

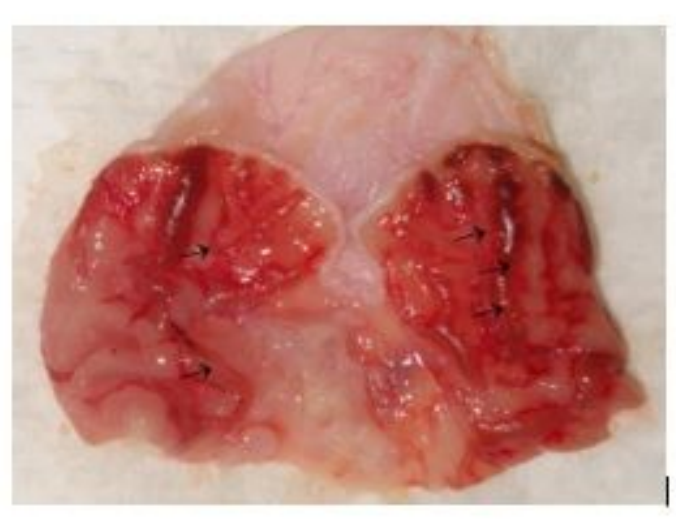

C

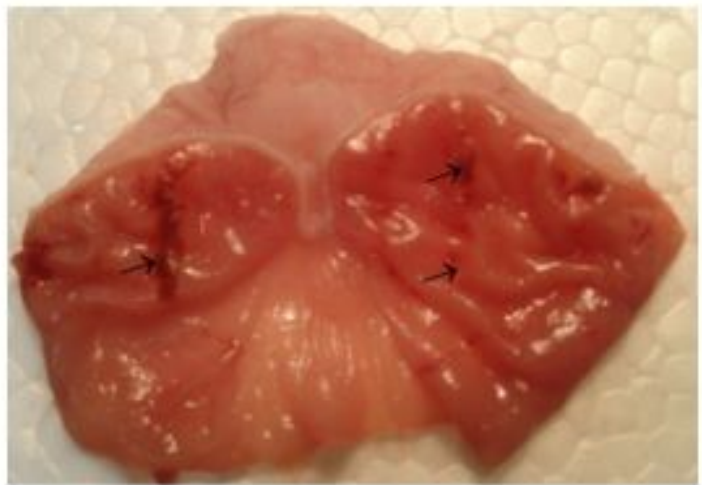

D

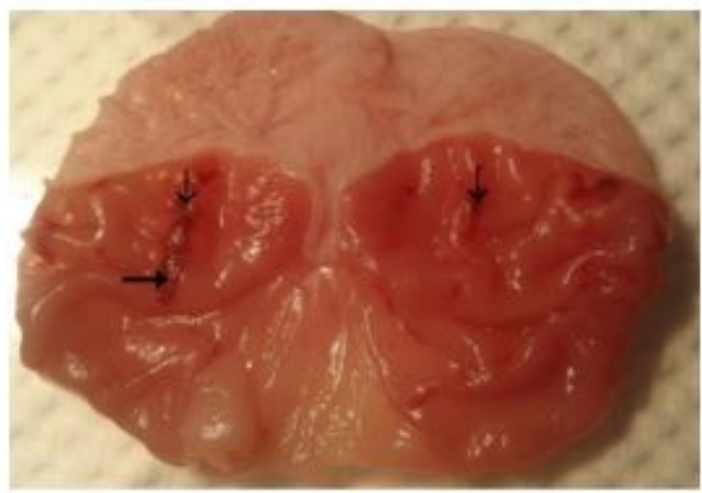

$\mathbf{E}$

\section{Figure 1}

Effect of $y$-mangostin on gross images of absolute ethanol-induced gastric damage in rats. (A) Normal control group showed intact gastric epithelium, (B) Ulcer control displays severe hemorrhagic ulceration of gastric epithelium, (C) \& (D) Experimental groups (10 mg/kg and $20 \mathrm{mg} / \mathrm{kg}$ Y-mangostin) showed (arrow) obvious reduction in the gastric lesions and (E) Omeprazole $(20 \mathrm{mg} / \mathrm{kg})$ showed mild injuries to gastric mucosa. 


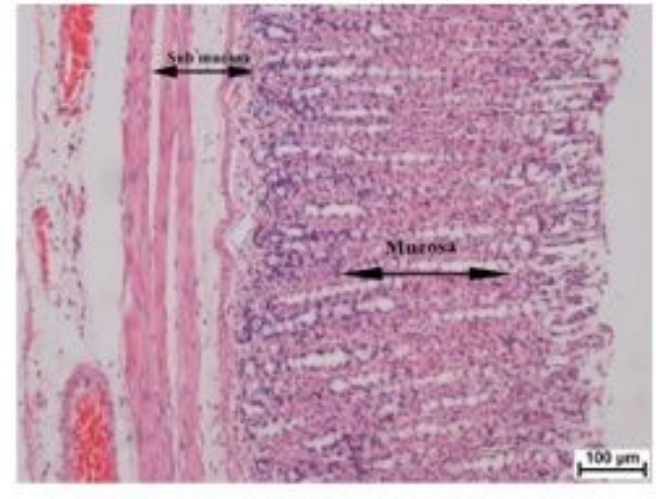

A

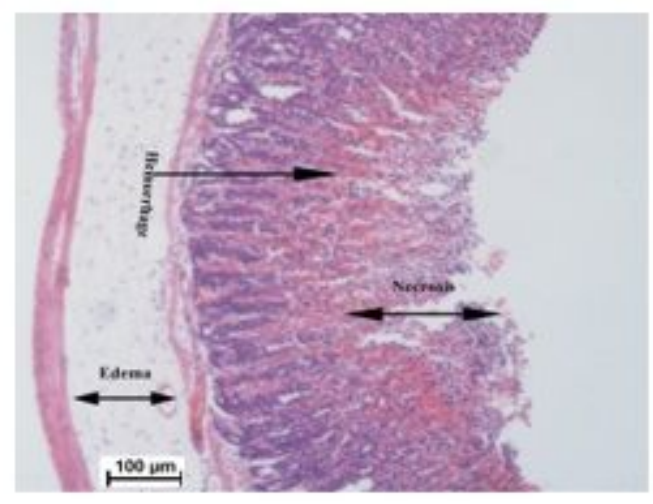

B

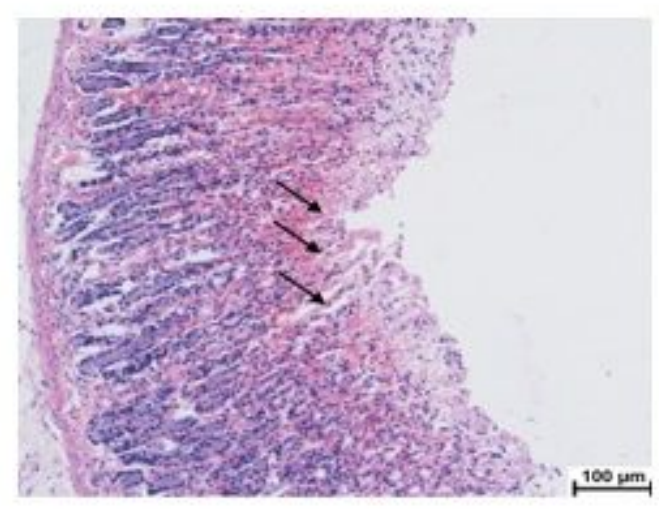

C

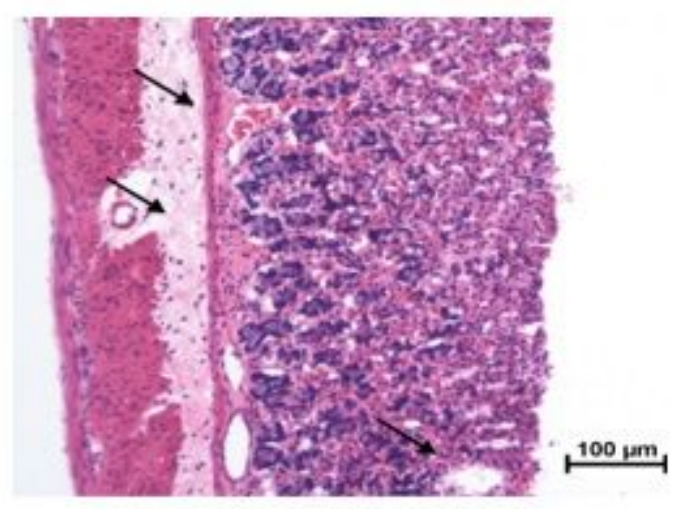

D

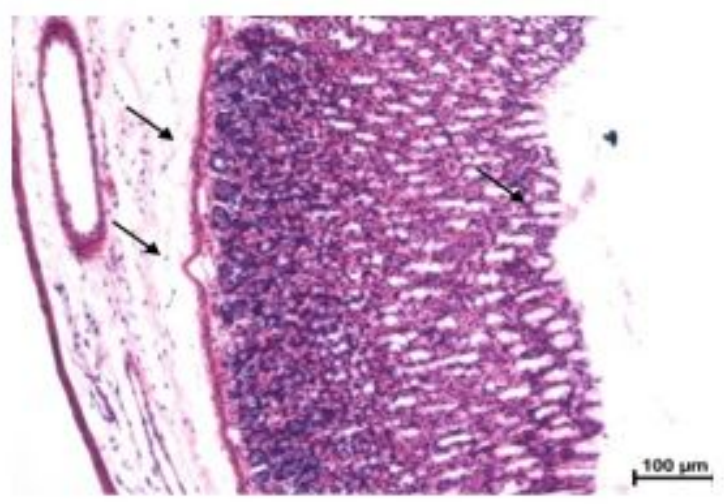

E

\section{Figure 2}

Effect of $y$-mangostin on the histology of gastric epithelium in ethanol-induced gastric mucosal injury in rats. (A) Normal control rats showed intact gastric mucosal epithelium, (B) Ulcer control stomach presenting severe mucosal injury along with deep necrosis, edema and hemorrhage of submucosal layer, (C) \& (D) Experimental groups (10 mg/kg and $20 \mathrm{mg} / \mathrm{kg}$ Y-mangostin) showed (arrow) reduced mucosal damage, (E) Omeprazole $(20 \mathrm{mg} / \mathrm{kg})$ showed mild mucosal injury. 


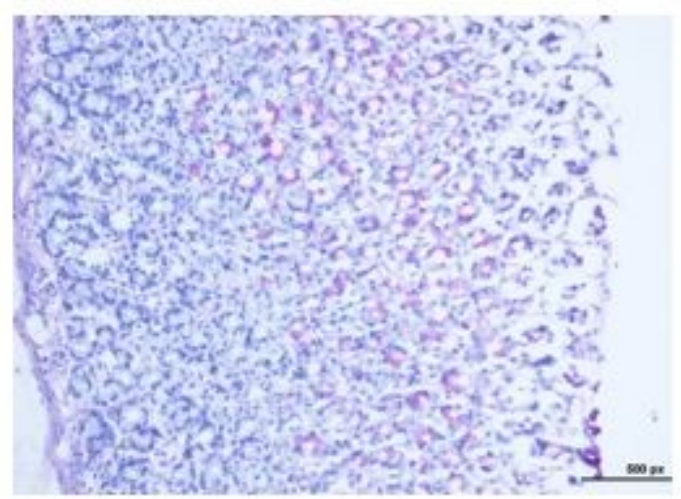

A

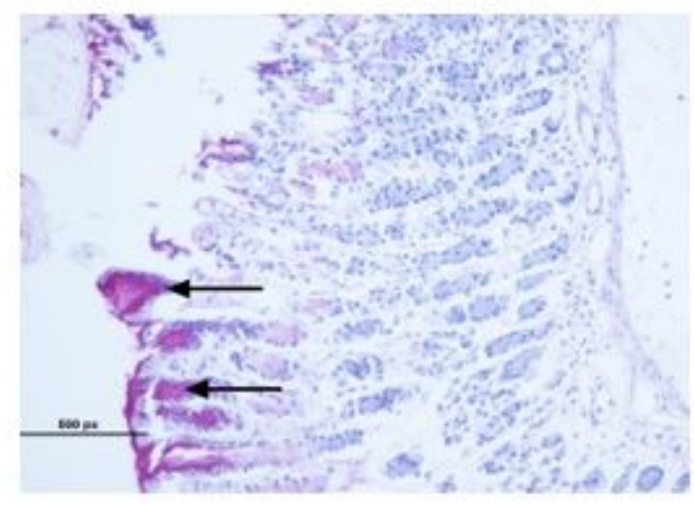

B

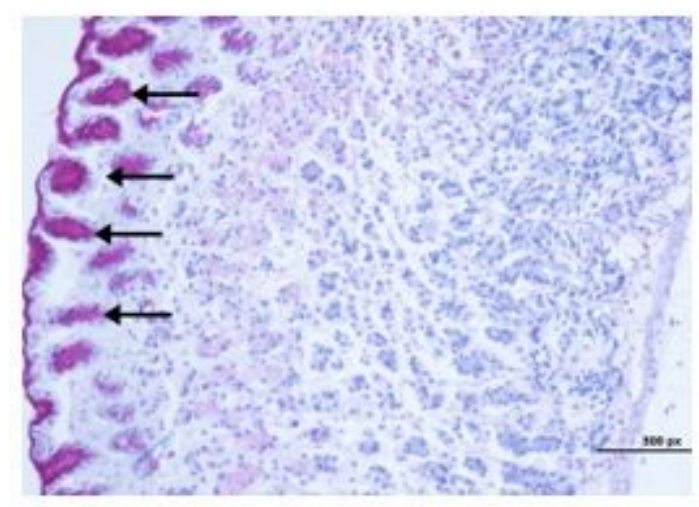

C

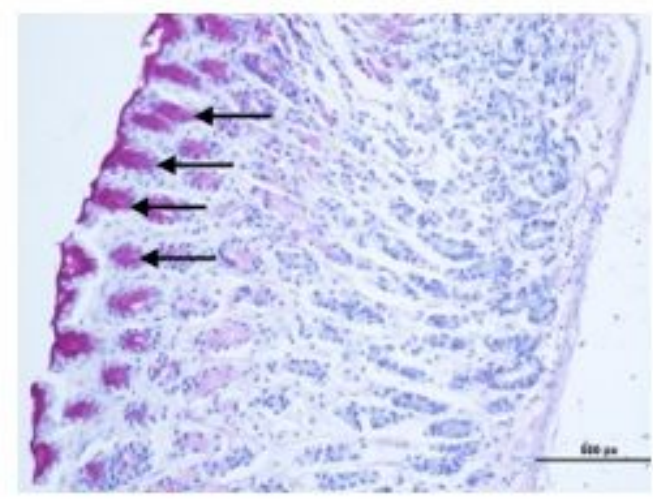

D

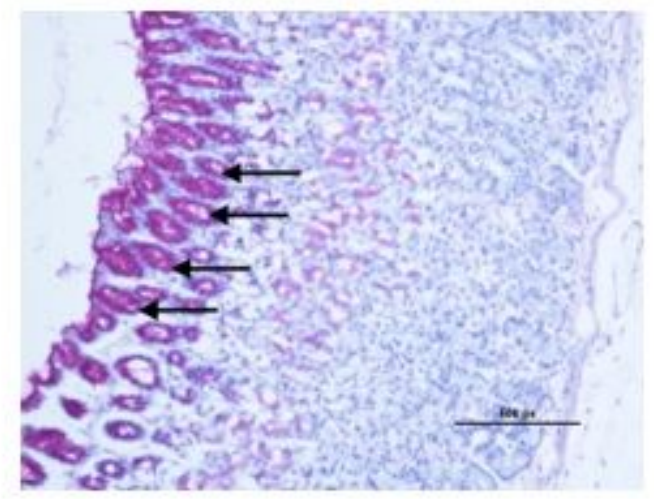

E

\section{Figure 3}

Effects of $y$-mangostin on PAS staining of gastric glycoproteins secretion in ethanol-induced stomach injury in rats. (A) Normal control group showing normal magenta color of gastric mucus glands, (B) Ulcer control group showed absence of PAS staining of gastric epithelium with severe mucosal injuries, (C) \& (D) Experimental groups (10 mg/kg and $20 \mathrm{mg} / \mathrm{kg} \mathrm{y}^{-m a n g o s t i n)}$ exhibited intense up-take of PAS stain. $\mathrm{Y}^{-}$ mangostin $20 \mathrm{mg} / \mathrm{kg}$ showed more intense PAS staining than the $\gamma$-mangostin $10 \mathrm{mg} / \mathrm{kg}$. (E) Omeprazole (20 mg/kg) exhibited intense PAS stain, where the black arrows specifies the glycoprotein appears as magenta stain (PAS stain 20x). 


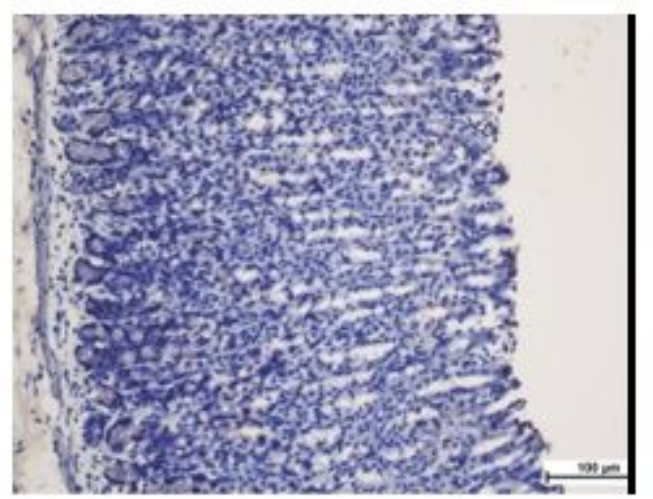

A

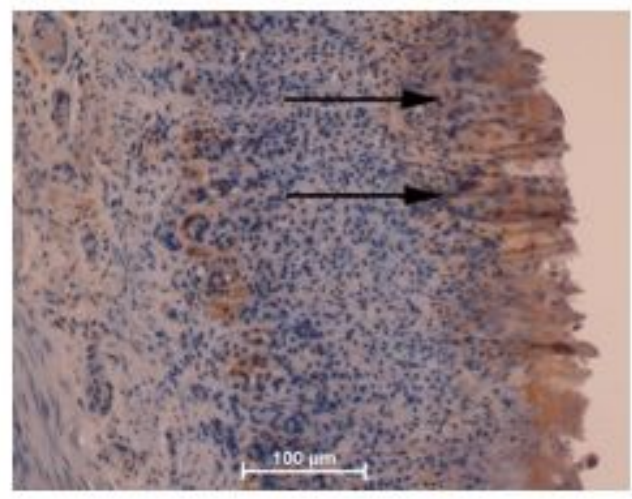

B

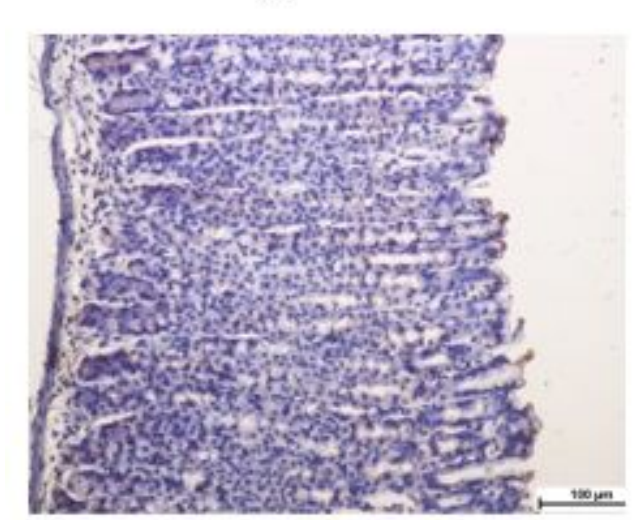

C

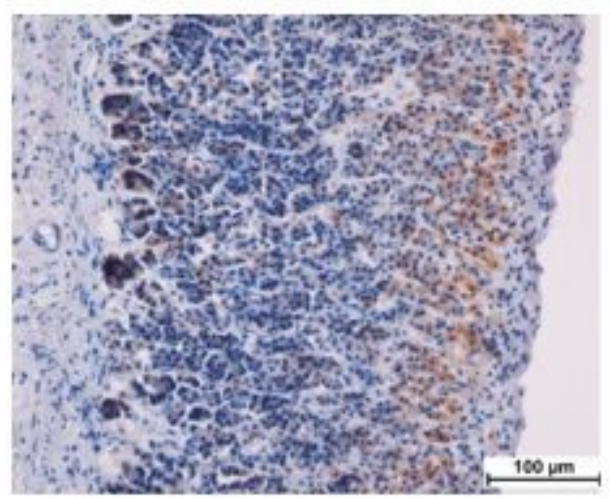

D

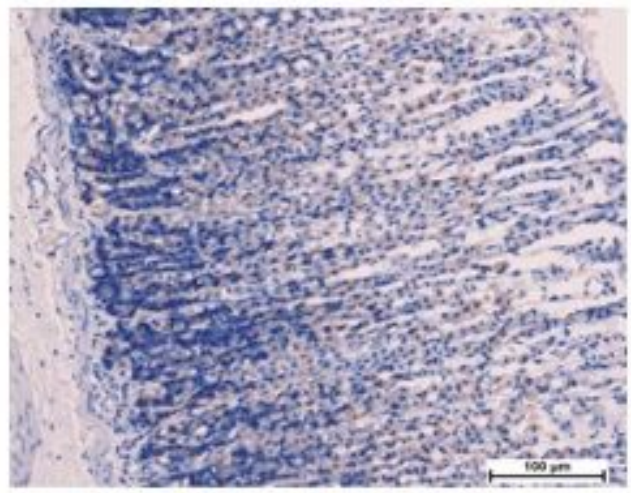

E

Figure 4

Effect of $y$-mangostin on the expression of Bax proteins of gastric mucosa in ethanol-induced stomach ulcer in rats. (A) Normal control group, (B) Ulcer control group up-regulate Bax protein, (C) \& (D) Experimental groups down regulate Bax protein (10 mg/kg and $20 \mathrm{mg} / \mathrm{kg}$ Y-mangostin) (E) Omeprazole (20 mg/kg down regulate Bax protein. Arrows indicate the proteins in situ (10x). 


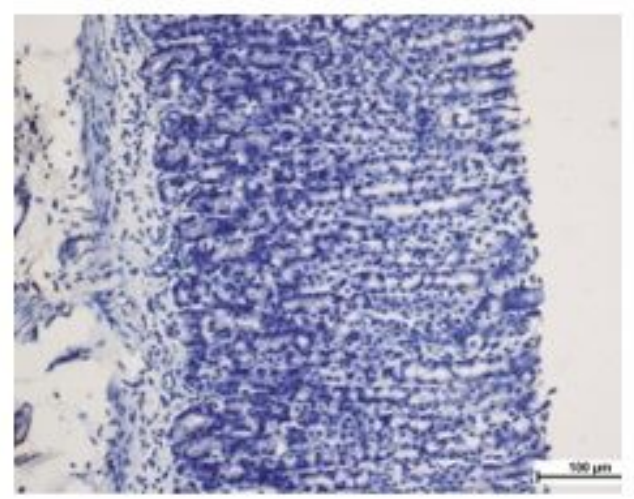

A

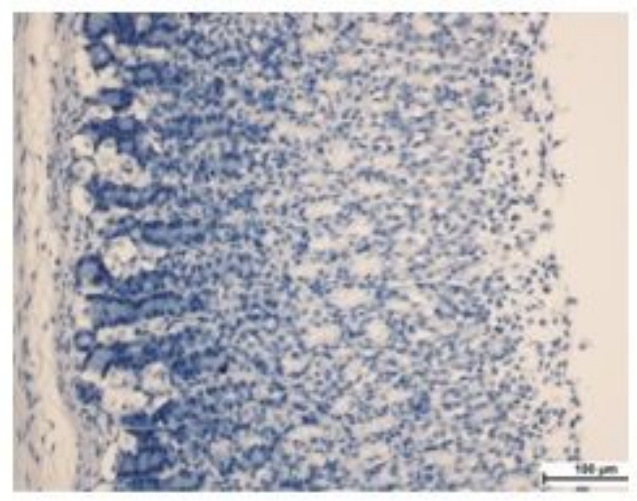

B

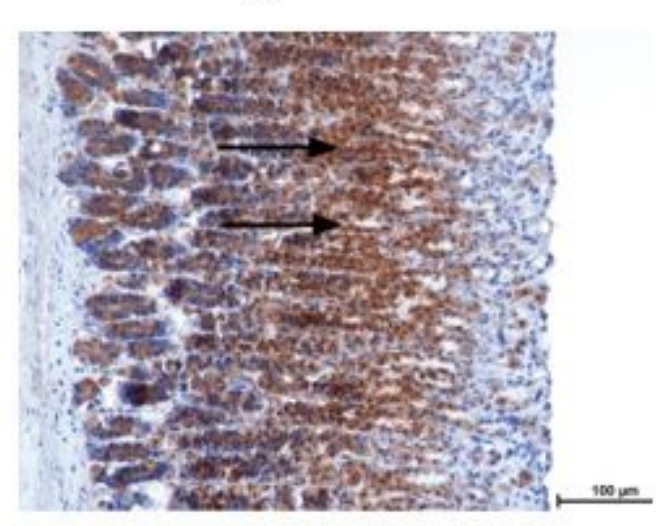

C

C

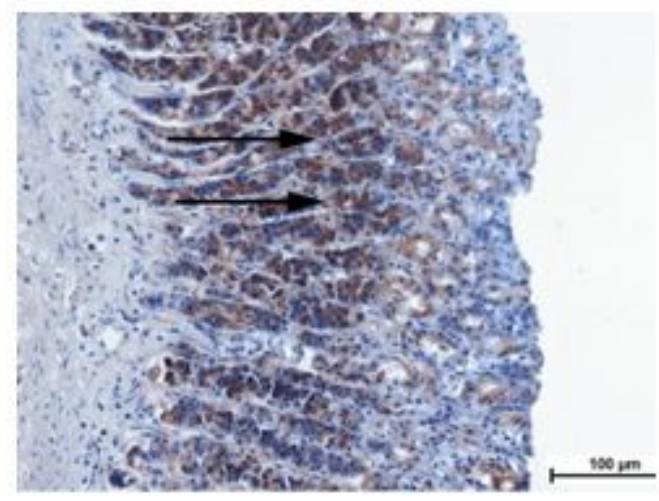

D

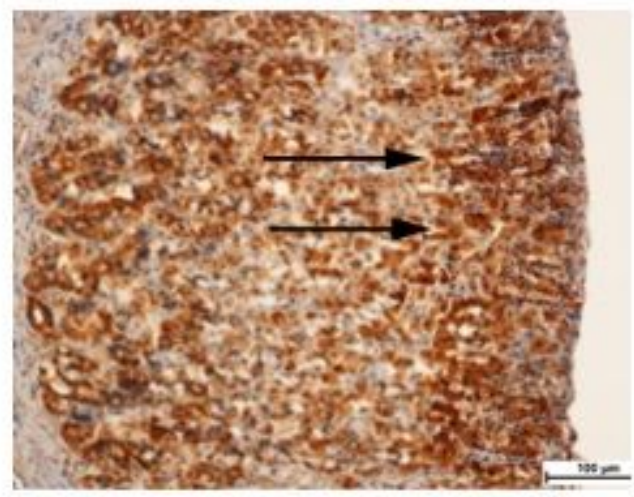

E

\section{Figure 5}

Effect of $\mathrm{y}$-mangostin on the expression of HSP 70 of gastric mucosa in ethanol-induced stomach ulcer in rats. (A) Normal control group, (B) Ulcer control group down regulate HSP 70 protein expression, (C) \& (D) Experimental groups up-regulate HSP 70 protein expression (10 mg/kg and $20 \mathrm{mg} / \mathrm{kg}$-mangostin) (E) Omeprazole $(20 \mathrm{mg} / \mathrm{kg}$ up-regulate HSP 70 protein expression. Arrows indicate the proteins in situ (10x). 

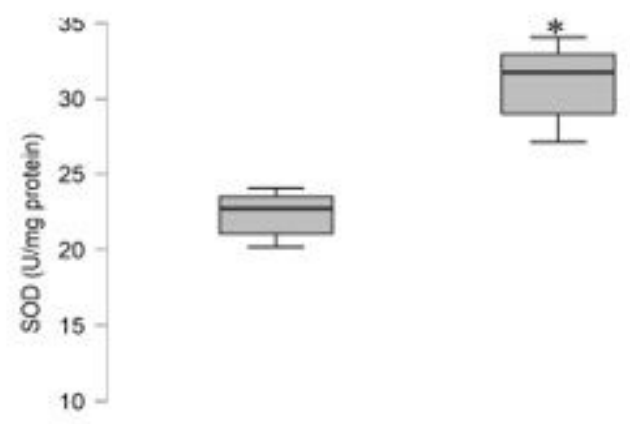

Normal control

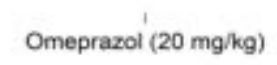

Ulcer control

mangostin (10 mg/kg)

mangostin (20 mg/kg)

Experimental groups
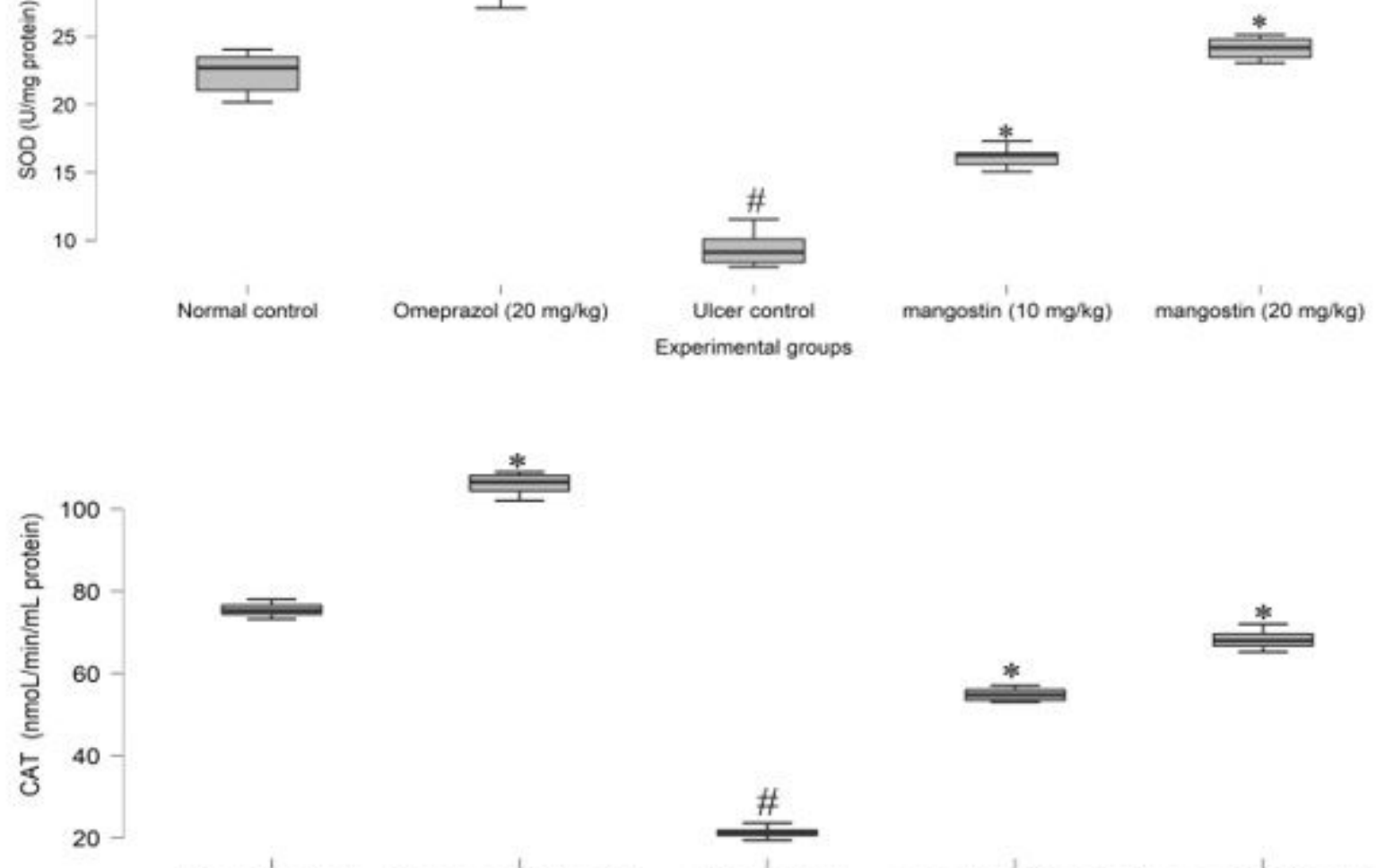

Normal control

Omeprazol (20 mg/kg)

Ulcer control
xperimental groups

mangostin (10 mg/kg) mangostin $20 \mathrm{mg} / \mathrm{kg}$
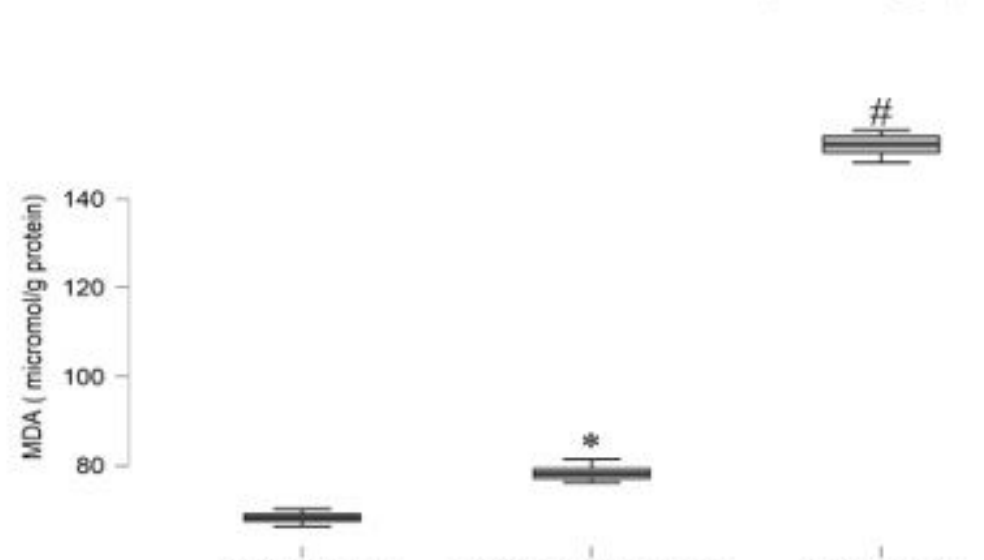

Normal control

Omeprazol (20 mg/kg)

Ulcer control Experimental groups

\section{Figure 6}

Box plot: Effect of the $y$-mangostin on the SOD, CAT and MDA of stomach tissue homogenate of rats. Statistical significant differences were examined using one way ANOVA and Tukey's posthoc multiple comparisons at $P<0.05$. Data expressed as mean \pm S.D. ( $n=6 /$ group). Significant difference at $\# P<$ 0.001 versus normal control group and $* P<0.001$ versus ulcer control group. 